\title{
Em torno da hermenêutica da escola: anatomia de uma política em mutação
}

Pedro Jorge Caetano ${ }^{1}$

\section{Resumo}

Procurando reconhecer uma inteligibilidade nas transformações fomentadas pelas políticas educativas dos últimos anos nas escolas portuguesas, este artigo apoia-se na analítica foucaultiana da governamentalidade enquanto instrumento crítico para uma interpretação das mudanças que estão ocorrendo na Europa e, em particular, em Portugal. Focando os processos, mais do que os resultados, revisita-se o curso realizado por Foucault no Collège de France - Sécurité, Territoire, Population - com o objetivo de traçar um paralelismo entre o reformismo das políticas educativas atuais, traduzidas num corpus legislativo, e a economia de poder especificada pelo neoliberalismo. Por este prisma, argumenta-se que os novos modos de governação das escolas, dos professores e dos estudantes visam progressivamente alcançar três desideratos estreitamente articulados entre si, a saber: a constituição de um milieu educativo favorável à circulação de pessoas, bens e informação; a normalização das condutas por meio da elaboração de standards; bem como a adoção da racionalidade da economia política no trabalho escolar. É pelo concurso destas três finalidades que o processo de autonomização das escolas se torna cada vez mais um instrumento-chave de governação das escolas, em detrimento do processo direto de administração estatal. A nova configuração semântica que acompanha este processo, centrada na autoavaliação, no desenvolvimento estratégico e na inovação pedagógica, destina-se a fazer impelir as escolas na realização de um trabalho hermenêutico sobre si próprias, operacionalizando ações de melhoria dos seus resultados, de modo a constituírem-se como escolas de qualidade.

\section{Palavras-chave}

Escola - Governamentalidade - Milieu - Segurança - Normalização.

1- Centro Interdisciplinar de Ciências Sociais (CICS.NOVA), Faculdade de Ciências Sociais e Humanas (FCSH/NOVA), Lisboa, Portugal. Contatos: caepedro@gmail.com; pedrocaetano@fcsh.unl.pt 


\section{On the hermeneutics of school: the anatomy of a changing politics}

\section{Abstract}

In an effort to recognize intelligibility in the transformations encouraged by the educational policies of recent years in Portuguese schools, this article draws on Foucault's analysis of "governmentality" as a critical instrument for interpreting the changes taking place in Europe and, especially, in Portugal. Focusing mainly on processes rather than on outcomes, we return to Foucault's course in the Collège de France - Sécurité, Territoire, Population - aiming at drawing a parallelism between the reformism of current educational policies, which are translated into a legislative corpus, and the economy of power specified by neoliberalism. From this point of view, it is argued that the new modes of governing schools, teachers and students are progressively aimed at achieving three closely interrelated goals, namely: the constitution of an educational milieu allowing for the circulation of people, goods and information; the normalization of behaviors by deploying standards; as well as the adherence to the political economy rationale in school work. It is through these goals that the process of school autonomy is increasingly becoming a key instrument of school governmentality, to the detriment of the direct process of state administration. The new semantic configuration, which follows this process centered on self-evaluation, strategic development and pedagogical innovation, aims to encourage schools to do hermeneutic work on themselves, using their autonomy to improve their performance in order to establish themselves as high-quality schools.

\section{Keywords}

School - Governmentality - Milieu - Security - Safety - Normalization.

\section{Introdução}

As duas últimas décadas têm sido pautadas, no conjunto dos países da OCDE, ${ }^{2}$ por um intenso voluntarismo reformista na esfera da educação (LINDBLAD; POPKEWITZ, 2004). Em geral, reconhece-se a determinação do Estado em descentralizar competências e responsabilidades educativas nos municípios e nas escolas. Paralelamente, reforça-se o papel de liderança dos diretores e a prestação de contas das escolas e agrupamentos, bem como se exorta à transparência dos processos e à liberdade de escolha das famílias

2- A OCDE, sigla de Organização para a Cooperação e o Desenvolvimento Econômico, é uma organização intergovernamental criada em 1961 por 20 países europeus e norte-americanos. Visando ao progresso econômico, a economia de mercado e a consolidação da democracia, conta atualmente com 35 países membros. Portugal foi um dos países fundadores desta organização que, em virtude de um processo de alargamento para fora da Europa e da América do Norte, integra neste momento o Japão, a Austrália, a Nova Zelândia, a Coreia do Sul, o Chile e Israel. 
(SCHLEICHER, 2012). Aponta-se a falta de comprometimento das escolas e dos professores pela falta de qualidade do ensino e insucesso escolar. E se a pluralidade de juízos acerca da realização do bem educativo entre os professores tem obstaculizado a unidade de ação em prol do bem comum (RESENDE, 2003), procede-se crescentemente a implementação de standards, como dispositivos políticos de integração e uniformização.

Nos Estados Unidos, essa medida tem originado o afunilamento do currículo, consubstanciado em um pequeno leque de disciplinas, e a um ensino-aprendizagem orientado quase exclusivamente para os resultados dos exames (SRIKANTAIAH, 2009). $\mathrm{Na}$ Europa, esse conjunto de medidas é vivido pelos professores como resultado da desprofissionalização docente (FROSTENSSON, 2015), pelo que não vislumbram no mesmo uma racionalidade inteligível:

[...] as mudanças atuais resultam da acumulação constante de uma sucessão de leis, cada uma estabelecendo novas responsabilidades, sem iniciar qualquer discussão aprofundada do que constitui a essência da profissão docente. (EURYDICE, 2008, p. 15).

Portugal, ainda que sob a promessa eternamente adiada da autonomia das escolas e da descentralização administrativa (LIMA; AFONSO, 1995), devido à sólida tradição centralista do país, constituía, até recentemente, mais concretamente até ao início do século XXI, um caso notório de divergência das trajetórias reformistas neoliberais implementadas nos Estados Unidos da América e na Inglaterra desde meados dos anos 80 do século passado, no que à governação das escolas diz respeito.

Na verdade, à margem do avanço do new public management (LIMA; AFONSO, 2014) e da desprofissionalização dos professores, ${ }^{3}$ que começavam a surtir os seus efeitos nesses países, em Portugal, durante mais de uma década, e face às "resistências da administração para iniciar uma efetiva política de descentralização e democratização do governo das escolas" (LIMA, 2009, p. 239), foram coexistindo duas agendas reformistas na governação do sistema educativo: a democrática, baseada na descentralização e na participação, e a técnica, alicerçada fundamentalmente no new public management, de tipo tecnocrático e instrumental (BARROSO, 2005; LIMA; AFONSO, 1995). Esta última, em grande parte por efeito das necessidades de um combate à ineficiência pública, à redução de custos e desburocratização, foi progressivamente ganhando terreno face à primeira, pelo que, no início do século XXI, Portugal surge decididamente alinhado com as políticas europeias de modernização do sistema educativo, "introduzindo-se novas modalidades de governação da educação através [...] de gestão centrada nos resultados escolares e numa racionalização das redes escolares” (LIMA, 2014, p. 1077).

\footnotetext{
3- A ênfase nos direitos profissionais dos professores ficou bem marcada ao longo dos anos noventa. Assim, e a propósito do Decreto-lei 1/98, de 2 de Janeiro, que visava expressamente a valorização da profissão docente, "nomeadamente quanto aos direitos de negociação coletiva, de participação no processo educativo, de formação e informação para o exercício da função educativa e de segurança na atividade profissional", o Decreto-lei 15/2007, de 19 de janeiro, nove anos volvidos, referia-se nestes termos à evolução ocorrida: "com o decorrer do tempo e pela forma como foi apropriado e aplicado, acabou por se tornar um obstáculo ao cumprimento da missão social e ao desenvolvimento da qualidade e eficiência do sistema educativo, transformando-se objetivamente num factor de degradação da função e da imagem social dos docentes". Deste modo, a uma avaliação docente centrada, primeiramente, na autoavaliação, sucede com o último Decreto-Lei uma avaliação predominantemente hierárquica e contemplando os resultados escolares dos alunos.
} 
Neste aspecto, pode-se falar com Lima (2009, p. 237), de uma autonomia heterogovernada, ${ }^{4}$ segundo uma forma de governo "mais centrada na eficácia e na eficiência da gestão e num conceito de autonomia como delegação política de novas responsabilidades e encargos por parte do Estado" (LIMA, 2009, p. 237).

0 objetivo do presente artigo é justamente o de poder contribuir para situar as transformações ocorridas à luz de um quadro teórico foucaultiano, procurando interpretálas com o recurso à analítica do poder desenvolvida por Foucault no seu curso no Collège de France, Sécurité, Territoire, Population (FOUCAULT, 2009). ${ }^{5}$ No centro da sua análise encontra-se o conceito de governamentalidade, o qual tem a "economia política como forma privilegiada de conhecimento e os aparatos de segurança como instrumento técnico principal" (FOUCAULT, 2009, p. 144).

A pertinência analítica deste conceito, por contraponto com o uso generalizado do termo governança, para compreender os processos políticos atuais de autonomização das instituições e dos indivíduos, prende-se essencialmente com duas razões que informam o método foucaultiano: as suas raízes crítica e pragmática (JOSE, 2010, p. 690). A governamentalidade possui:

[...] raizes filosóficas e históricas mais ricas e amplas; é um termo de meta-análise que pode ser usado para refletir criticamente os resultados da investigação sobre a governança. (AMOS, 2010, p. 24).

$\mathrm{Na}$ verdade, enquanto a governança permanece ao nível institucional, a governamentalidade permite a articulação entre o governo dos outros e o governo de si próprio - a performance e o sujeito performativo. A abordagem, centrada no paralelismo entre as mudanças em Portugal e a transcrição inglesa do referido curso, não se centra na formação de subjetividades, mas sim na articulação dos modos de governo das escolas, dos professores e dos estudantes.

\section{O problema da escola no âmbito da eficácia das políticas públicas: do território educativo ao milieư da comunidade educativa}

$\mathrm{Na}$ última dezena de anos, as escolas públicas portuguesas têm vindo a conhecer momentos de intensa agitação no que diz respeito às repercussões que uma série de alterações legislativas têm produzido na administração e gestão das escolas, bem como no trabalho dos profissionais do ensino. Estas alterações, profundamente interligadas, visam nomeadamente à reordenação da rede escolar, a racionalização do modo de governação das

\footnotetext{
4- Em itálico no original.

5- Doravante usar-se-á STP como abreviatura de Sécurité, Territoire, Population.

6- Optou-se pelo uso do termo milieu, em francês, de resto, tal como na tradução inglesa de STP, em lugar de uma possível tradução para português pelo seu equivalente funcional, a palavra meio, com o objetivo de realçar a importância do significado técnico do termo, a partir do qual 0 mesmo começou a ser utilizado pelos cientistas naturais. Embora a palavra meio em português conserve a polissemia da palavra milieu em francês, a partir do latim medius, o uso que aqui se procura destacar é o seu uso técnico, justamente sublinhado por Foucault em STP, onde, nas notas no final da página 36, o pensador francês faz referência ao aspecto mecânico inerente ao uso original do termo por parte de cientistas naturais, Lamarck, Newton ou Buffon, "na emergência da ideia de milieu na segunda metade do século dezoito, através da noção de 'forças penetrantes' (forces pénétrantes)".
} 
escolas e uma nova hierarquização da carreira docente. A justificação última das mesmas prende-se com a melhoria do sucesso dos alunos e da qualidade das aprendizagens, ao mesmo tempo em que se procura combater o abandono escolar.

Trata-se, no entender do Ministério da Educação de Portugal, de introduzir mais justiça e eficácia tanto na vida das escolas, como na dos professores e dos alunos. Mas, se a diferenciação e hierarquização da carreira docente, proposta na revisão do Estatuto da Carreira Docente (ECD) pelo Decreto-Lei n. ${ }^{0} 15 / 2007,{ }^{7}$ conheceu um significativo retrocesso cinco anos mais tarde com o Decreto-Lei 41/2012, onde, em nome da estabilidade e da concórdia nas escolas, se restabelecia uma carreira única dos professores, já as recentes alterações no regime de autonomia das escolas vieram exercer uma significativa influência na transformação do trabalho escolar.

Com efeito, e ainda que a diretriz de uma política administrativa de proximidade começasse logo a ser desenhada pelo Decreto-Lei 115-A/98, no qual se pugnava por uma organização e gestão da administração educativa centrada na escola e nos respetivos territórios educativos, apenas mais recentemente, pelo Decreto-Lei 75/2008, se assistiu verdadeiramente a um incremento generalizado do processo regulado de autonomização dos estabelecimentos de ensino. Este último documento legislativo é particularmente iluminativo relativamente ao carácter pragmático do processo: "a autonomia constitui não um princípio abstrato ou um valor absoluto, mas um valor instrumental”. (PORTUGAL, Decreto-Lei 75/2008).

Nesse sentido, o processo de autonomia é conduzido passo a passo na direção desejada pela tutela, pelo que as escolas, na sua demonstração de capacidade auto-organizativa, terão de lhe prestar contas através, nomeadamente, dos instrumentos de autoavaliação e de avaliação externa, uma vez que, "a maior autonomia tem de corresponder maior responsabilidade”. (PORTUGAL, Decreto-Lei 75/2008).

Reconhece-se, assim, o esboço de um roteiro, pelo qual as escolas, pilotadas a partir do seu estado de menoridade, poderão alcançar no final do seu trajeto a condição de maioridade. 0 timoneiro deste empreendimento, rosto primordial da responsabilidade perante a tutela, é constituído na figura do diretor de estabelecimento. Este é incumbido de construir e encabeçar o projeto estratégico de estabelecimento, onde constam as grandes linhas de individuação da escola ou agrupamento de escolas. Cabe ao diretor reunir as necessárias capacidades de liderança no processo, apresentando resultados, dado que a condição de performatividade é inerente ao próprio regime de governação que aqui se desenha. E é com este propósito de garantir a eficácia das estratégias, que o Decreto-Lei 137/2012 procede ao "reajustamento do processo eleitoral do diretor, conferindo-lhe maior legitimidade através do reforço da exigência dos requisitos para o exercício da função". As incumbências do diretor alargam-se, entre outras, à contratação do pessoal docente, ao estabelecimento de parcerias ou ainda à nomeação dos cargos de gestão intermédia.

Sendo o diretor o mandatário de uma soberania de proximidade, ${ }^{8}$ presente em todos os momentos da vida escolar, a condição de democraticidade é resolvida com a

7- Todos os documentos legislativos consultados e mencionados neste artigo dizem respeito à República Portuguesa.

8- A soberania de proximidade deve aqui ser entendida como uma forma de governamentalidade que, através dos instrumentos da autonomia e da descentralização, faz articular mais eficazmente a transferência hierárquica de poder dos níveis mais centrais para os níveis mais locais. 0 
legitimação da transferência de poder, anteriormente enformada na relação pedagógica, para a comunidade educativa, da qual, por inerência, os professores continuam a ser membros, mas já não os únicos signatários no que concerne às decisões importantes na vida do estabelecimento.

De resto, a criação do Conselho Geral, órgão máximo do agrupamento que confere e aprova o mandato do diretor, visa à representação de todas as partes interessadas no processo educativo: os pais e encarregados de educação, bem como a comunidade local, "designadamente de instituições, organizações de caráter económico, social, cultural e científico" (PORTUGAL, Decreto-Lei 137/2012). Neste ponto, o anterior Decreto-Lei 75/2008, cujo propósito visava ao aprofundamento da autonomia das escolas, é categórico:

Em primeiro lugar, trata-se de reforçar a participação das famílias e comunidades na direção estratégica dos estabelecimentos de ensino. É indispensável promover a abertura das escolas ao exterior e a sua integração nas comunidades locais. (PORTUGAL, Decreto-Lei 75/2008).

Pelo que fica claramente exposto que a efetiva participação da comunidade local, não apenas dos pais e encarregados de educação, mas, no fundo, de todas as forças e sinergias do meio, constitui doravante o campo alargado de atuação das práticas de poder referentes à escola. Cabe à escola e, portanto, aos que nela trabalham, enquadrar-se positivamente no meio em que está inserida:

[...] uma tal intervenção [da comunidade local] constitui também um primeiro nível, mais direto e imediato, de prestação de contas da escola relativamente àqueles que serve. (PORTUGAL, Decreto-Lei 75/2008).

Deste ponto de vista, o processo de autonomização das escolas ocorre em um quadro político alargado que privilegia o reforço de desconcentração de poderes do Estado central para as autarquias. Neste processo centrífugo, a escola não apenas se assume como elemento importante da comunidade educativa territorializada, na articulação entre o nível micro do estabelecimento e o nível macro estatal, como também, por sua vez, é ela própria nutrida na comunidade, codesenvolvendo-se com ela na produção do meio indispensável à sua individuação.

Por conseguinte, o território educativo, adquirindo por esta via uma legitimidade acrescida no campo de atuação da escola, não pode continuar a ser olhado como um

Estado, com todos os seus aparatos, aproxima-se das pessoas, mas a lógica da governamentalidade permanece a da soberania, uma vez que a delegação de competências e a autonomia da decisão dos níveis mais periféricos é fortemente condicionada. Já anteriormente, nos anos 80 , o Ministério da Educação português havia ensaiado outra fórmula de soberania de proximidade, através da criação de estruturas intermédias entre o Estado e as escolas: as delegações regionais de educação, entretanto desativadas. Conforme salienta Lima (2009, p. 235), "0 resultado será muito mais o da delegação de certas competências para as direções-regionais de educação, novo nível de administração criado, do que de transferência de competências para as escolas, desta feita instituindo uma administração de tipo centralizado-desconcentrado (LIMA, 2009, p. 235). Desaparecida a estrutura intermédia, a delegação de poderes conferida diretamente pelo Estado ao diretor da escola não faz reduzir a dependência deste a respeito daquela. Como refere novamente Lima (2009, p. 247-48) "[...] o diretor e os restantes órgãos de direção e gestão, poderão ser dissolvidos a qualquer momento pelo Governo, na sequência de processo de avaliação externa ou de ação inspetiva que comprovem prejuízo manifesto para o serviço público ou manifesta degradação ou perturbação da gestão (artigo 35º". 
simples suporte administrativo de extensão da jurisdição do Ministério da Educação, mas como um meio dinâmico que empresta materialidade e engenho à própria escola. Estamos próximos daquilo que Foucault designa, no seu curso de 1978 no Collège de France Sécurité, Territoire, Population (FOUCAULT, 2009) -, por constituição de um milieu, neste caso, um milieu educativo.

Nesse curso, abordando ao longo do século XVIII a problemática das interrelações entre a cidade, a soberania e o território, Foucault vislumbra naquele período a emergência de uma nova economia de poder, no momento em que a crescente autonomia das cidades colocava o Estado à prova no que dizia respeito à melhor maneira de governar um território. 0 desafio colocado pelas cidades motivou a redefinição da articulação entre macro e micropolíticas no interior do Estado, gerando importantes transformações na relação entre espaço e território.

Segundo Foucault (2009, p. 26):

[...] a cidade ainda tinha uma definição jurídica e administrativa que a isolava e marcava de forma bastante específica em comparação com outras áreas e espaços do território. Em segundo lugar, a cidade era tipicamente confinada dentro de um espaço apertado, murado, que tinha muito mais do que apenas uma função militar.

Uma vez que a cidade era econômica e socialmente mais heterogénea do que o campo:

[...] em termos gerais, o que estava em questão no século XVIII era a questão da abertura espacial, jurídica, administrativa e económica da cidade: voltar a situar a cidade num espaço de circulação. (FOUCAULT, 2009, p. 26-27).

Traçando um paralelismo entre o problema espacial que a cidade coloca ao Estado e os problemas que a escola coloca à tutela à entrada do século XXI, verificam-se certas similitudes, em uma escola fechada sobre si mesma, enquanto campo de atuação privilegiada do poder disciplinar (RAMOS DO Ó, 2003), com poucas ou nenhumas relações com as outras escolas ou o meio circundante.

No fundo, uma escola feita à medida da relação pedagógica, tal qual a escola republicana idealizada por Durkheim (2012) nos primórdios do século XX; uma escola que, colocada à prova com a entrada de novos públicos (ALMEIDA; VIEIRA, 2006), pressente o exterior sob a forma de ameaças e de perigos (RESENDE, 2010), procurando segurança (sûreté) no recolhimento do seu espaço isomórfico (CAETANO; GOUVEIA, 2016).

Por isso mesmo, abrir a escola, ressituando-a no espaço territorializado da comunidade educativa, é uma forma de tentar responder ao problema da escola. Promovendo a produção de um meio que seja produtivo (no sentido foucaultiano do termo), autorregulador e caracterizado por certa incerteza e capacidade de inovação, onde a circulação de pessoas diferentes e de saberes, bem como a partilha de recursos e de informação, prevaleça sobre a autarcia rotineira do modelo de reprodução escolar. Foucault designa este meio de milieu: "o espaço em que se desenrolam uma série de elementos incertos é, penso eu, mais ou menos o que se pode chamar de milieu" (FOUCAULT, 2009, p. 35). 


\section{O desbloqueio do modelo da relação pedagógica na gênese da governamentalidade da escola}

De acordo com Foucault, no decorrer do século XVIII, observa-se a gênese de um outro modo de exercício do poder, relativamente ao qual a criação do milieu, enquanto espaço político de intervenção, se constitui como um correlato funcional necessário. Assim, e constituindo-se o território como "o elemento fundamental tanto do principado de Maquiavel como da soberania jurídica do soberano, tal como definido por filósofos ou teóricos jurídicos" (FOUCAULT, 2009, p. 134), a arte do governo quedava-se "sempre ao nível da formulação de princípios gerais de direito público” (FOUCAULT, 2009, p. 134).

Ela encontrava-se "presa entre uma estrutura de soberania excessivamente grande, abstrata e rígida, por um lado, e, por outro, um modelo da família que era demasiado estreito, fraco e insubstancial" (FOUCAULT, 2009, p. 134), uma vez que, não existindo ainda nem uma ciência política nem uma ciência econômica consolidadas naquele tempo, a ideia de administração "apenas se referia à gestão de um pequeno conjunto que compreendia a família e o lar" (FOUCAULT, 2009, p. 140). Deste modo, "com a família e o pai, por um lado, e o Estado e a soberania, por outro, a arte do governo não conseguiu encontrar a sua própria dimensão" (FOUCAULT, 2009, p. 140).

No entender de Foucault, o despontar das novas racionalidades política e econômica, e a posterior emergência da economia política, permitiram desbloquear um quadro de gestão administrativa demasiado refém da lógica jurisdicional e disciplinar, abrindo deste modo um campo inteiramente novo de ação: a gestão da população. Nesse sentido, as palavras de Foucault são categóricas:

[...] a família passará de modelo a instrumento; ela tornar-se-á um instrumento privilegiado para o governo da população e não um modelo quimérico de bom governo. A mudança do nível do modelo para o do instrumento em relação à população é absolutamente fundamental. (FOUCAULT, 2009, p. 141).

Quer isto dizer que tanto a família como o território perdem muito do seu caráter de centralidade e de intocabilidade para descender à condição material de ferramenta ou utensílio, no fundo, à categoria de coisa ou de variável. Deste modo:

[...] a partir de meados do século XVIII, a família realmente aparece nessa relação instrumental com a população, nas campanhas sobre mortalidade, campanhas sobre o casamento, vacinações e inoculações, e assim por diante. (FOUCAULT, 2009, p. 141).

Também o território, sobretudo nas suas formas mais localizadas, pode-se converter, adquirindo maior autonomia, em um precioso instrumento de aproximação entre os governados e os governantes.

A generalização da relação instrumental e da atitude pragmática a ela associada abrange igualmente o modo de exercício do poder. Assim: 
[...] não se trata de impor uma lei aos homens, mas da disposição das coisas, ou seja, de empregar táticas em vez de leis, ou, na medida do possível, de empregar leis como táticas. (FOUCAULT, 2009, p. 137).

Por isso mesmo, tanto na sua operacionalização procedimental como até mesmo no que se refere às referências normativas do juízo moral, o avanço do liberalismo sobre as práticas de soberania tem o efeito, como refere Lemke (2002, p. 50), de solapar o recurso generalizado aos métodos disciplinares, com todo o seu repertório codificado de interdições como fonte de legitimidade, para, em lugar dos mesmos, erigir o bem da liberdade como regra de justiça a observar.

Consequentemente, o exercício do poder sob o regime liberal visa, antes de mais, à influência instrumental sobre a conduta da população, mesmo considerando que este poder:

[...] não exclui as formas consensuais ou o recurso à violência, significa apenas que a coerção ou o consenso são reformulados como meios de governo entre outros, são "elementos" ou "instrumentos", mais do que a "fundação" ou "fonte" do poder. (LEMKE, 2002, p. 50).

Para enfatizar as características desse novo regime de exercício de poder, Foucault socorre-se de um renascentista francês, Guillaume de La Perrière, para quem um "bom governador deve possuir paciência, sabedoria e diligência” (FOUCAULT, 2009, p. 137). Sabedoria que, alerta-nos Foucault (2009, p. 137),:

[...] não é exatamente a sabedoria da tradição, sob a forma das leis divinas e humanas, da justiça e da equidade, porém a sabedoria do conhecimento das coisas, dos objetivos a serem atingidos e da "disposição" que se tem de ter com vista a atingi-los.

Essa paciência e sabedoria prática que, em alternativa a uma regulação estatutária da ordem administrada pela codificação do direito, se impõe doravante como fórmula tática de atingir a ordem nos contextos atuais de incerteza. Epitomizando esta conceção positiva da ordem, podemos recorrer, dentro de um manancial de literatura científica sobre as problemáticas atuais do sistema educativo, às recomendações de Andreas Schleicher, coordenador do Programa Internacional de Avaliação de Alunos da OCDE, para quem "o objetivo do passado era a padronização e a conformidade, hoje trata-se de ser engenhoso, de personalizar experiências educacionais" (SCHLEICHER, 2012, p. 36).

Para Schleicher (2012, p. 36):

[...] os sistemas educacionais precisam cada vez mais de identificar como os indivíduos aprendem de forma diferente e promover novas formas de provisão educacional que levem o estudante a aprender das maneiras mais propícias.

Ora, essas reformas, a terem lugar no ensino-aprendizagem, exigem que o modelo da relação pedagógica assente na referência magistral (CAETANO; GOUVEIA, 2016), deixe de representar um verdadeiro obstáculo ao governo liberal das escolas. Efetivamente, este governo, enquanto governo da população, caracteriza-se, sobretudo, pelo favorecimento 
da circulação e não pela reprovação dos estudantes. Por este motivo, devem ser produzidos permanentemente arranjos educativos e pedagógicos que possibilitem aos estudantes poderem aprender ao seu ritmo e consoante os seus interesses e necessidades. 0 mesmo é dizer que a relação pedagógica já não se constitui como a finalidade última da prática docente, pois ela é somente um instrumento entre outros de envolvimento de cada aluno no seu próprio processo de ensino-aprendizagem.

A exigência da flexibilização e diferenciação curricular em todos os níveis educativos, a multiplicação das fileiras alternativas ao ensino regular, a promoção do trabalho colaborativo entre docentes, a flexibilização do calendário e horário escolares, e assim por diante, são alguns dos elementos táticos passíveis de contínua reformulação, tendo em conta a variabilidade dos contextos de atuação.

Estas expressões de autonomia encontram-se vinculadas à dimensão estratégica do agrupamento: as trajetórias de individuação da escola, aquilo que esta se propõe a fazer, o modo como se irá proceder para atingir os resultados desejados. 0 projeto educativo da escola ou agrupamento de escolas, bem como o regulamento interno, são dos mais importantes instrumentos de gestão estratégica que as escolas têm ao seu dispor. À escala do milieu educativo, os mesmos fazem a articulação pragmática entre "a política educativa e pedagógica que o estabelecimento escolhe conduzir, tendo em conta os constrangimentos com os quais se confronta" (BOUTINET, 1997, p. 209).

Deste modo, e seguindo um regime de envolvimento em plano (THÉVENOT, 2006), a escola ou o agrupamento de escolas são impelidas a realizar um trabalho hermenêutico sobre si próprias, no sentido de operacionalizarem ações estratégicas, de melhorarem os seus resultados e de se constituírem como escolas de qualidade. ${ }^{9}$ Encontrando-se no ponto de sutura entre as macropolíticas pensadas para a escola e as micropolíticas do estabelecimento, estamos em presença dos instrumentos de governamentalidade por excelência, no sentido de que, nas palavras de Foucault, em L'origine de l'herméneutique de soi, "o ponto de contacto, onde [a maneira] os indivíduos são dirigidos pelos outros se articula com a maneira como eles se conduzem eles mesmos, é o que eu posso chamar, creio, "governo"." (FOUCAULT, 2013, p. 38-39).

De resto, este trabalho hermenêutico da escola encontra-se bem patente, por exemplo, no Decreto-lei 41/2012, onde na alínea a do ponto 2 do Artigo 9. ${ }^{\circ}$-A, relativamente à integração dos instrumentos de gestão, se pode ler que o projeto educativo:

[...] constitui um documento objetivo, conciso e rigoroso, tendo em vista a clarificação e comunicação da missão e das metas da escola no quadro da sua autonomia pedagógica, curricular, cultural, administrativa e patrimonial, assim como a sua apropriação individual e coletiva [destaque nosso]. (PORTUGAL, Decreto-Lei 41/2012).

9- Não deixa de ser particularmente significativa esta insistência tipicamente moderna nos vocábulos de melhoria e de autonomia, no que se refere às instituições ou às pessoas. A tónica na necessidade de transformação, tão cara a Foucault, leva Lindblad e Popkewitz (2004), oportunamente, a refletir sobre esta urgência de reestruturação a partir de um conceito de lan Hacking, o conceito de elevator words, palavras que, associadas a dispositivos, produzem efeitos acríticos na orientação da conduta das pessoas e das instituições, delimitando os seus domínios de experiência. Deste modo, estes autores concetualizam "a reestruturação não como um projeto explicado somente pelas suas consequências e resultados, mas como uma 'palavra elevatória' [elevator word] que se inter-relaciona com práticas discursivas particulares para construir conjuntos de relações e princípios para ordenar como os objetos de escolaridade são vistos, falados, dispostos e sentidos" (LINDBLAD; POPKEWITZ, 2004, p. xix). 
A palavra aqui sublinhada, "apropriação", é suficientemente significativa para se convocar novamente o vocabulário foucaultiano. Na verdade, e como contraparte das técnicas de governo, as técnicas de si constituem igualmente um precioso mecanismo de transformação da escola, neste caso, por via de um trabalho de subjetivação, isto é, de transformação de si por si mesma. Pelo que, para a escola poder realizar a sua autonomia, tanto objetiva como subjetivamente, a mesma deverá dotar-se de um conjunto alargado de técnicas analíticas, tanto reflexivas como objetivas, destacando-se nestas últimas a influência decisiva da estatística, dominante nas técnicas de diagnóstico, de prevenção, de monitorização e de autorregulação da escola.

\section{Segurança, normalização, mais-valia}

Como Foucault não deixa de sublinhar ao longo de Sécurité, Territoire, Population, um dos mais importantes fatores no desbloqueamento da arte do governo e, consequentemente, da passagem de um regime de administração para a governamentalidade, diz respeito a um fator técnico: a estatística (FOUCAULT, 2009, p. 140). Inicialmente designando o conhecimento do Estado acerca de si próprio (FOUCAULT, 2009, p. 411), dos seus recursos, das suas forças e fraquezas, a estatística foi, de acordo com o regime de governo mobilizado, explorada de forma muito distinta.

Assim, sob a égide do equilíbrio entre Estados e o aparato administrativo dominado pela ótica da soberania, a análise estatística era colocada frequentemente em segredo, de modo a prevenir que os rivais pudessem usufruir das vantagens de conhecer o real valor do seu oponente. Todavia, com a emergência da economia política, começou a tomar forma outro modo de gerir os recursos, mais focado no controlo dos processos do que na prevenção das causas:

[...] o objetivo principal desta gestão será não tanto evitar que as coisas aconteçam, como assegurar que as regulações necessárias e naturais sigam o seu curso, ou mesmo criar regulações que possibilitem aquelas seguir o seu curso. (FOUCAULT, 2009, p. 451).

A evolução ulterior desta perspectiva não se pode desligar da gênese da estatística no início do século XVIII, nomeadamente, do conjunto de trabalhos que se incluem na "síntese de Gauss-Laplace” (STIGLER, 1986, p. 158), isto é, do reconhecimento e caracterização da distribuição normal dos fenômenos. Foucault dá como exemplo a descoberta da taxa de morbilidade da varíola no século XVIII e dos desenvolvimentos que levaram, primeiro, à demonstração da sua curva normal, para, posteriormente, e a partir de análises mais finas, verificar-se a existência de uma pluralidade de curvas normais de morbilidade referentes a uma série de variáveis de contexto.

Com base neste conjunto de observações, foram produzidos esforços no sentido de alinhar as curvas normais mais desviantes em relação à curva normal geral, de modo a ajustá-las a esta última (FOUCAULT, 2009, p. 90). Foucault designa este ajustamento pelo termo de "normalização": 
[...] a operação de normalização consiste em estabelecer uma interação entre estas diferentes distribuições de normalidade e [em] agir para trazer a mais desfavorável em linha com a mais favorável. (FOUCAULT, 2009, p. 91).

Ao invés do que sucede no regime da soberania, onde a classificação normal/anormal decorre da conformidade a uma norma fixada, no regime liberal, "o normal vem primeiro e a norma é deduzida a partir dele, ou a norma é fixa e desempenha o seu papel operacional com base neste estudo de normalidades" (FOUCAULT, 2009, p. 91). Nas palavras de Foucault (2009, p. 91), "então, eu diria que o que está aqui em jogo não é mais a normatização (normation), mas sim a normalização no sentido estrito". Isso significa que a normalização tem uma base empírica, que a normatização não tem. Enquanto o processo de normatização consiste essencialmente em um processo de adaptação, a normalização refere-se a um processo de ajustamento por otimização. Trata-se de controlar e ajustar uma característica desvantajosa de um determinado fenômeno, de maneira a aproximá-la das características mais vantajosas, fazendo sobressair os aspectos de análise tática e estratégica.

No âmbito dos processos de normalização, Foucault cedo coloca no centro da análise a problemática da segurança, nomeadamente os modos como ela é produzida. E no sentido de estabelecer claramente a distinção entre o regime da soberania e o regime liberal de governação, introduz uma subtil variação semântica relacionada com o significado dos termos franceses sureté e sécurité, a qual foi posteriormente conservada na tradução inglesa (FOUCAULT, 2009) com os termos de safety e security, respectivamente. Se os dois termos se podem remeter mutuamente em uma aproximação de minimização de potenciais perigos e riscos, o modo de os perspetivar, segundo um ponto de vista técnico, difere consideravelmente.

Safety refere-se fundamentalmente à proteção preventiva do ambiente, das coisas e das pessoas, "significando abordar os perigos por meio de salvaguardas e procedimentos" (STAVRIANAKIS et al., 2011, p. 1). Mas, "embora a segurança [safety] se centre em soluções técnicas, a segurança [security] visa maximizar a circulação de elementos num contexto de risco" (STAVRIANAKIS et al., 2011, p. 3). Nesse sentido, "o objetivo de um modo de segurança [security] não é a prevenção de perigos específicos ou a proteção de espaços específicos, mas a governança de um meio [milieu]" (STAVRIANAKIS et al., 2011, p. 3).

Não obstante, os dois modos de governo coexistem e complementam-se. Assim, a segurança [safety] evidencia-se na elaboração de normas e de tecnologias de controlo das condutas para prevenir ameaças, enquanto a segurança [security] opera no modo como os diversos elementos circulam no milieu. Esses elementos, identificados como pertinentes, são categorizados e classificados, para serem posteriormente organizados em séries estatísticas. Quanto mais longas forem estas séries, maior será o rigor probabilístico no cálculo dos riscos (LUHMANN, 1993) e maior será a capacidade preditiva de intervenção no milieu. Isso possibilita aos atores operarem "com uma métrica de certeza dentro de uma zona de incerteza sempre em declínio" (STAVRIANAKIS, 2011, p. 5). A segurança sob o modo de security é então concebida como método de pilotagem assente não em protocolos e guiões [safety], mas sim com o recurso a bancos de dados e a relatórios periódicos 
baseados no tratamento matemático-estatístico dos mesmos. Essas técnicas têm como efeito a normalização dos dados, isto é, a sua redução a standards empíricos.

É justamente nesse quadro alargado de desenvolvimento do modo de security que, com a melhoria da qualidade do ensino em mira, a OCDE tem promovido desde o final dos anos 90 a comparabilidade sistemática dos resultados escolares dos diferentes países membros. 0 seu instrumento mais representativo, concebido estrategicamente para acelerar reformas educacionais, o PISA (Programme for International Student Assessment), é um dos principais catalisadores da mudança, a par da:

[...] descentralização (sob o slogan 'autonomia das escolas') e a avaliação externa, as quais, como frequentemente é afirmado, não se encontram em lados diametralmente opostos, mas são partes inter-relacionadas da governança do sistema educativo. (OCDE, 2004, p. 66).

Para a consecução deste instrumento, têm-se multiplicado, quer à escala internacional quer nacional, testes estandardizados aos estudantes dos diversos níveis de ensino. Obtêm-se, deste modo, extensas bases de dados sobre as escolas, os estudantes e os seus professores (OCDE, 2009), as quais contêm informação que permitem traçar o perfil e monitorizar a evolução dos mesmos, seja ao nível agregado ou ao nível individual. Em suma, informação indispensável para um apropriado governo das escolas, dos professores e dos estudantes. ${ }^{10}$

Indicadores de qualidade educativa são monitorizados preferencialmente com o recurso ao benchmarking (melhores práticas), em um ambiente de competição entre escolas para elevar cada vez mais os standards gerais. Os rankings de escola traduzem o posicionamento relativo de cada uma delas. Contudo, e face à contestação de que são alvo (MELO, 2009), outros rankings têm sido elaborados, com recurso à informação de contexto, permitindo, na prática, proceder ao processo de normalização das escolas. A partir da média de resultados escolares em cada cluster de escolas, obtêm-se os valores dos standards para cada um desses mesmos clusters e, consequentemente, os desvios dos valores esperados para cada uma das escolas ou agrupamentos. Observamos, assim, os traços do processo de normalização referido por Foucault: o ajustamento da performatividade das escolas por otimização.

0 aperfeiçoamento da normalização encontra o seu mais recente avanço no desenvolvimento de uma ferramenta não paramétrica, denominada DEA (data envelopment analysis; em português, análise envoltória de dados). Utilizada sobretudo na literatura da economia da educação, o DEA constitui-se como uma alternativa à análise de regressão múltipla, principal instrumento na base da elaboração de rankings. Esses estudos consideram os rankings como um método simplista de qualificar escolas, úteis fundamentalmente

\footnotetext{
10- Efetivamente, o regime técnico de governamentalidade requer a vigilância, o conhecimento e o monitoramento do comportamento natural da população, em detrimento da soberania repressiva ou da microfísica do poder das técnicas disciplinares. Com base neste conhecimento, estabelecem-se normalidades estatísticas, as quais serão conhecidas e apropriadas pela população. Neste sentido, como afirmam Popkewitz e Linblad (2001, p. 131), "ao aplicar um cálculo de probabilidade, o raciocínio estatístico constrói nossa compreensão de como as crianças aprendem, da realização escolar e dos atributos sociais e psicológicos presumidos como causa de fracassos escolares e da relação dos indivíduos ao progresso social e econômico".
} 
para os pais dos estudantes, na medida em que apenas mostram as probabilidades de maximizar os resultados escolares dos seus filhos (RAUDENBUSCH; WILLMS, 1995). Ao invés, os estudos que utilizam o DEA e que procuram refletir a eficiência de cada escola e de cada professor podem-se constituir de especial importância para os administradores e responsáveis políticos (BADRI; MOHAIDAT; EL MOURAD, 2014).

A prestação de contas neste último caso pretende isolar a prática efetiva em meio escolar do contexto escolar constituído pela origem social dos estudantes e pelo ambiente normativo do meio, o que não acontece no caso dos rankings (HANUSHEK, 1986). Acarinhada pela OCDE (2008), a utilização do DEA introduz diretamente nas políticas públicas educativas o modelo da mais-valia da economia política.

Assim sendo, o efeito de escola dos professores procura ser deduzido independentemente do efeito das tradicionais variáveis de contexto e variáveis individuais. Dessa forma, um novo campo de práticas de avaliação inaugura-se, com recurso à criação de plataformas de benchmarking, as quais podem ser consultadas on-line por cada diretor de escola ou outros responsáveis educativos. Um exemplo disso mesmo é a plataforma BESP (PORTELA, 2014) desenvolvida pela Universidade Católica do Porto. De resto, estudos recentes em Portugal têm sugerido que os resultados dos rankings e as práticas inspetivas tradicionais diferem substancialmente dos resultados adotando o modelo da mais-valia (SARRICO; ROSA, 2009).

\section{Conclusão}

A perspetiva da governamentalidade ensaiada por Foucault no Collège de France vem no seguimento das principais ideias desenvolvidas no seu curso anterior - Il faut défendre la société -, mormente a de considerar a forma jurídica, na análise das manifestações do poder, como uma tecnologia entre outras, com a finalidade de constranger as condutas; ou ainda a de trazer o modelo da guerra e a questão da segurança para o primeiro plano da reflexão crítica.

Depois de Sécurité, Territoire, Population, Foucault prossegue com o curso La biopolitique, no qual procura analisar o liberalismo, no coração da sociedade e já não do Estado, entendido como uma maneira de conduzir as coisas, um método do exercício de um governo que se estende para além do Estado para outras esferas da sociedade. No final do percurso deste tríptico, Foucault realiza uma verdadeira anatomia dos diversos regimes de exercício do poder político, no fundo, como refere Lemke (2002, p. 58), Foucault, na esteira de Marx, faz uma "crítica da anatomia política". O liberalismo, em particular, como instrumento crítico da realidade, solicita "uma anatomia política do corpo" (LEMKE, 2002, p. 60):

[...] em que não só o corpo individual, mas também os órgãos e instituições coletivos (administrações públicas, universidades, etc.), empresas e estados devem ser "magros", "aptos", "flexíveis" e "autónomos" (LEMKE, 2002, p. 60).

Deste modo, importa concetualizar o neoliberalismo não apenas como uma ideologia, mas também como uma atitude, puramente abstraída na "forma técnica 
adequada à ação governamental, mais do que com a legitimação da soberania política” (MCGARRY, 2013, p. 145).

A heuristicidade deste plano de análise para interpretar corretamente as mutações ocorridas no sistema educativo (desde os anos 80 em alguns países ocidentais, e desde o final dos anos 90, em Portugal) aparenta ser evidente. Efetivamente, o problema da articulação entre as políticas públicas e as práticas efetivas de ensino-aprendizagem, a implementação de standards como modo preferencial de integração sistêmica, de uniformização e de autorregulação, bem como a generalização das práticas de benchmarking, relembranos que pensar a escola em termos de soberania e prescrições comuns, é alheio à sua aproximação em termos de milieu, segurança, normalização ou mais-valia.

Esses processos, atualmente em curso em Portugal, correspondem à materialização efetiva de uma trajetória modernizadora que, estimulada por uma conjuntura internacional priorizando a eficiência e a eficácia, acabou por vingar após anos de hesitação quanto à orientação das reformas a realizar.

Com efeito, a orientação técnica das reformas inerente à governamentalidade não elimina a razão de Estado própria da soberania, porventura matizada em uma soberania de proximidade, mas tende a obliterar os anseios e as promessas alimentadas pela geração que fez o Vinte e Cinco de Abril em Portugal, mormente no que diz respeito ao aprofundamento da democratização dos poderes.

A futura orientação do trabalho nas escolas requererá cada vez mais dos docentes uma inserção em rede e uma profissionalidade coletiva (OCDE, 2016). Não obstante, a amplitude de transformação das escolas e do trabalho docente está dependente do modo como os arranjos de segurança se combinam com os arranjos de soberania, quer a nível nacional quer a nível local e institucional, mormente no que refere à necessária articulação entre o governo das escolas, o governo dos professores e o governo dos alunos; na certeza, porém, de que neste momento se constituem bolsas de resistência corporativa e práticas de subjetivação como práticas imanentes de liberdade. E é neste sentido que, tal como o sujeito se constitui através de práticas de liberdade, por entre as fissuras na soberania e a ascensão da governamentalidade, o trabalho hermenêutico de uma escola em transformação pode ainda contribuir, como era o anseio de Foucault, para a sua melhoria enquanto locus de liberdade, para além dos standards.

\section{Referências}

ALMEIDA, Ana Nunes; VIEIRA, Marina Manuel. A escola em Portugal: novos olhares, outros cenários. Lisboa: Imprensa de Ciências Sociais, 2006.

AMOS, Karin. Governance and governmentality: relation and relevance of two prominent social scientific concepts for comparative education. Educação e Pesquisa, São Paulo, v. 36 (n. Especial), p. 23-38, abr. 2010.

BADRI, Masood; MOHAIDAT, Jihad; EL MOURAD, Tarek. Measuring the efficiency of public schools using data envelopment analysis - An exploratory study. Journal of Education and Practice, v. 5, n. 37, p. 215-232, 2014.

BARROSO, João. 0 Estado, a educação e a regulação das políticas públicas. Educação \& Sociedade, Campinas, v. 26, n. 92 (Especial), p. 725-751, out. 2005. 
BOUTINET, Jean Pierre. Antropologia do projeto. Lisboa: Instituto Piaget, 1997.

CAETANO, Pedro; GOUVEIA, Luis. Entre o modelo magistral e a responsabilidade social: controvérsias em torno da avaliação dos professores e a concepção "justa" do mandato docente. Terceiro Milénio, v. 6, n. 1, p. 236-265, jan./jun. 2016.

DURKHEIM, Émile. L'éducation morale. Paris: PUF, 2012.

EURYDICE. Levels of autonomy and responsibility of teachers in Europe. Bruxelas: European Commission, 2008.

FOUCAULT, Michel. L'origine de l'herméneutique de soi. Conférences prononcées à Dartmouth Collège, 1980. Paris: Vrin, 2013.

FOUCAULT, Michel. Security, territory, population: lectures at the Collège de France, 1977-1978. New York: Palgrave; MacMillan, 2009. Edição estabelecida por Michel Senellart, sob a direção de F. Ewald e A. Fontana.

FROSTENSSON, Magnus. Three forms of professional autonomy: de-professionalisation of teachers in a new light. Nordic Journal of Studies in Educational Policy, 2015. Disponível em: <http://dx.doi.org/10.3402/ nstep.v1.28464>. Acesso em: 28 jul. 2017.

HANUSHEK, Eric A. The economics of schooling: production and efficiency in public schools. Journal of Economic Literature, v. 24, n. 3, p. 1141-1177, Sep. 1986.

JOSE, Jim. A (con)fusion of discourses? Against the governancing of Foucault. Social Identities, v. 16, n. 5 , p. 689-703, 2010.

LEMKE, Thomas. Foucault, Governmentality, and Critique. Rethinking Marxism, v. 14, n. 3, p. 49-64, 2002.

LIMA, Licínio C. A democratização do governo das escolas públicas em Portugal. Sociologia, Porto, v. 19, p. 227-253, 2009.

LIMA, Licínio C. A gestão democrática das escolas: do autogoverno à ascensão de uma pós-democracia gestionária? Educação \& Sociedade, Campinas, v. 35, n. 129, p. 1067-1083, out./dez. 2014.

LIMA, Licínio C.; AFONSO, Almerindo J. The promise land. Educational Review, v. 47, n. 2, p. 165-172, 1995.

LINDBLAD, Sverker; POPKEWITZ, Tom. Educational restructuring: (re)thinking the problematic of reform. In: LINDBLAD, Sverker; POPKEWITZ, Tom. (Ed.). Educational restructuring: international perspectives on traveling policies. Greenwich: Information Age, 2004. p. vii-xxxi.

LUHMANN, Niklas. Risk: a sociological theory. New York: A. de Gruyter, 1993.

MCGARRY, Michael Gerard. "To read, write, and cast accounts": Foucault, governmentality and education in upper Canada/Canada West. 2013. Ph.D. thesis - Department of Humanities, Social Sciences and Social Justice Education, OISE, University of Toronto, Toronto, 2013. Disponível em: <http://hdl.handle. net/1807/35903>. Acesso em: 21 dez. 2017. 
MELO, Maria Benedita de Portugal. 0s professores do ensino secundário e os rankings escolares: reflexos da reflexividade mediatizada. Vila Nova de Gaia: Fundação Manuel Leão, 2009.

OCDE. Creating effective teaching and learning environments: first results from TALIS, 2009. Disponível em: $<$ http://dx.doi.org/10.1787/607814526732>. Acesso em: 27 jul. 2017.

OCDE. Measuring improvements in learning outcomes: best practices to assess the valueadded of schools, 2008. Disponível em: <http://www.oecd.org/edu/preschoolandschool/ measuringimprovementsinlearningoutcomesbestpracticestoassessthevalueaddedofschools.htm $>$. Acesso em: 28 jul. 2017.

OCDE. Supporting teacher professionalism: insights from TALIS 2013, 2016. Disponivel em: <http://www.oecd. org/publications/supporting-teacher-professionalism-9789264248601-en.htm>. Acesso em: 27 jul. 2017.

OCDE. What makes school systems perform? Seeing school systems through the prism of PISA. Paris: OECD, 2004.

POPKEWITZ, Tom; LINDBLAD, Sverker. Estatísticas educacionais como um sistema de razão: relações entre governo da educação e inclusão e exclusão sociais. Educação \& Sociedade, Campinas, v. 22, n. 75. p. 111-148, 2001. Disponível em: <http://dx.doi.org/10.1590/S0101-73302001000200008>. Acesso em: 21 dez. 2017.

PORTELA, Maria Conceição. Benchmarking in public services: the cases of health and education in Portugal, 2014. Disponível em: <http://www.uma.es/media/tinyimages/file/20141114.pdf>. Acesso em: 26 jul. 2017.

PORTUGAL. Decreto-lei 1/98, de 2 de Janeiro. Altera (terceira alteração) o Estatuto da Carreira dos Educadores de Infância e dos Professores dos Ensinos Básico e Secundário. Diário da República, Lisboa, n. ${ }^{0}$ 1/1998, Série I-A de 1998-01-02.

PORTUGAL. Decreto-Lei 15/2007, de 19 de janeiro. Altera (sétima alteração) o Estatuto da Carreira dos Educadores de Infância e dos Professores dos Ensinos Básico e Secundário aprovado pelo Decreto-Lei n. ${ }^{0}$ 139-A/90, de 28 de Abril, bem como à respetiva republicação. Diário da República, Lisboa, n. 14/2007, Série I.

PORTUGAL. Decreto-lei 41/2012, de 21 de fevereiro. Procede à 11. a alteração do Estatuto da Carreira dos Educadores de Infância e Professores dos Ensinos Básico e Secundário. Diário da República, Lisboa, n. ${ }^{\circ}$ 37/2012, Série l.

PORTUGAL. Decreto-Lei 75/2008, de 22 de abril. Aprova o regime de autonomia, administração e gestão dos estabelecimentos públicos da educação pré-escolar e dos ensinos básico e secundário. Diário da República, Lisboa, n. ${ }^{\circ}$ 79/2008, Série I.

PORTUGAL. Decreto-lei 75/2010, de 23 de junho. Altera (décima alteração) o Estatuto da Carreira dos Educadores de Infância e dos Professores dos Ensinos Básico e Secundário. Diário da República, Lisboa, n. ${ }^{0}$ 120/2010, Série I. 
PORTUGAL. Decreto-Lei 115-A/98, de 4 de maio. Aprova o regime de autonomia, administração e gestão dos estabelecimentos públicos da educação pré-escolar e dos ensinos básico e secundário, bem como dos respetivos agrupamentos. Diário da República, Lisboa, n. ${ }^{0}$ 102/1998, $1^{0}$ Suplemento, Série I-A.

PORTUGAL. Decreto-Lei 137/2012, de 2 de julho. Altera (segunda alteração) o Decreto-Lei 75/2008, de 22 de abril, que aprova o regime jurídico de autonomia, administração e gestão dos estabelecimentos públicos da educação pré-escolar e dos ensinos básico e secundário, e procede à sua republicação. Diário da República, Lisboa, n. ${ }^{0}$ 126/2012, Série I.

RAMOS DO Ó, Jorge. 0 governo de si mesmo: modernidade pedagógica e encenações disciplinares do aluno liceal (último quartel do século XIX - meados do século XX). Lisboa: Educa, 2003.

RAUDENBUSH, Stephen W.; WILLMS, J. Douglas. The estimation of school effects. Journal of Educational and Behavioral Statistics, v. 20, n. 4, p. 307-335, 1995.

RESENDE, José Manuel. A sociedade contra a escola? A socialização política escolar num contexto de incerteza. Lisboa: Instituto Piaget, 2010.

RESENDE, José Manuel. 0 engrandecimento de uma profissão: os professores do ensino secundário público no Estado Novo. Lisboa: Fundação Calouste Gulbenkian; Fundação para a Ciência e Tecnologia, 2003.

SARRICO, Cláudia S., ROSA, Maria João. Measuring and comparing the performance of Portuguese secondary schools: a confrontation between metric and practice benchmarking. International Journal of Productivity and Performance Management, v. 58, n. 8, p. 767-786, 2009.

SCHLEICHER, Andreas (Ed.). Preparing teachers and developing school leaders for the $21^{\text {st }}$ century: lessons from around the world, 2012. Disponível em: <http://dx.doi.org/10.1787/9789264174559-en>. Acesso em: 25 jul. 2017.

SRIKANTAIAH, Deepa. How state and federal accountability policies have influenced curriculum and instruction in three states: common findings from Rhode Island, Illinois, and Washington, 2009. Disponível em: <http://www.cep-dc.org/displayDocument.cfm?DocumentlD=217>. Acesso em: 29 jul. 2017.

STAVRIANAKIS, Fearnley et al. Human practices green paper: safety, security, preparedness: an orientation to biosecurity today, 2011. Disponível em: <http://anthropos-lab.net/wp/publications/2011/05/safetysecurity-preparedness-green-paper-may-2011.pdf>. Acesso em: 29 jul. 2017.

STIGLER, Stephen M. The history of statistics: the measurement of uncertainty before 1900. Cambridge: The Belknap Press of the Harvard University Press, 1986.

THÉVENOT, Laurent. L’action au pluriel: sociologie des régimes d'engagement. Paris: La Découverte, 2006.

Recebido em: 14.08.2017

Revisões em: 01.12.2017

Aprovado em: 20.02.2018 
Pedro Jorge Caetano é doutor em sociologia do conhecimento, da cultura e da educação pela Faculdade de Ciências Sociais e Humanas (FCSH/NOVA) e investigador integrado no Centro Interdisciplinar de Ciências Sociais (CICS.NOVA) da mesma universidade. Tem participado em diversos projetos científicos nacionais relacionados com 0 gênero, a desigualdade e humilhação nas escolas, as escolhas escolares dos jovens, e os Territórios Educativos de Intervenção Prioritária (TEIP). 